\title{
Axillary Lymph Node
}

National Cancer Institute

\section{Source}

National Cancer Institute. Axillary Lymph Node. NCI Thesaurus. Code C12904.

One of approximately 20-30 lymph nodes in chain formation that traverse the concavity of the underarm to the clavicle. 